Revue internationale de l'économie sociale

Recma

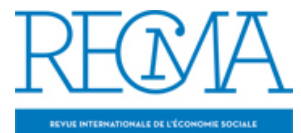

\title{
Les coopératives artisanales sous Vichy, apport au débat
}

\section{Jacques Moreau}

Numéro 288, avril 2003

URI : https://id.erudit.org/iderudit/1022195ar

DOI : https://doi.org/10.7202/1022195ar

Aller au sommaire du numéro

Éditeur(s)

Institut de l'économie sociale (IES)

ISSN

1626-1682 (imprimé)

2261-2599 (numérique)

Découvrir la revue

Citer ce document

Moreau, J. (2003). Les coopératives artisanales sous Vichy, apport au débat.

Revue internationale de l'économie sociale, (288), 10-10.

https://doi.org/10.7202/1022195ar d'utilisation que vous pouvez consulter en ligne.

https://apropos.erudit.org/fr/usagers/politique-dutilisation/ 


\section{LES COOPÉRATIVES ARTISANALES SOUS VICHY, APPORT AU DÉBAT}

Suite à la publication de l'article de Cédric Perrin intitulé "L'instrumentalisation des coopératives artisanales sous Vichy " dans le $n^{\circ} 286$ de la Recma, paru en novembre 2002 (pp. 71-80), Jacques Moreau, président d'honneur de la Caisse centrale de Crédit coopératif et président de la Fondation du Crédit coopératif, a fait parvenir le texte suivant à la rédaction.

$n$ relisant tardivement l'intéressante étude $\neg$ de Cédric Perrin concernant les coopéraـtives artisanales sous Vichy, publiée dans le numéro de novembre dernier, j'ai été surpris par la note $\mathrm{n}^{\circ} 39$, dans laquelle l'auteur se demande "comment la CCCC, qui, elle, survit, a traversé l'épuration "...

Cette question m'a paru bizarre: l'auteur me parait confondre la liquidation des organismes publics ou parapublics créés par le gouvernement de Vichy, qui a été opérée à la Libération (de façon d'ailleurs très partielle), avec le châtiment des Français individuellement accusés d'avoir collaboré avec l'ennemi (ce qui est l'épuration à proprement parler).

S'agissant de la Caisse centrale, qui a été - en gros jusqu'à 1988 - un élément du très vaste réseau aujourd'hui pratiquement disparu des établissements financiers spécialisés satellites du Trésor, il convient de rappeler que, créée par un décret-loi de 1938 pour dispenser des concours aux coopératives de consommation et aux coopératives ouvrières de production, elle avait vu sa compétence étendue aux coopératives artisanales par un décret de 1939. Sans doute a-t-on déjà souvent observé que le " régime Daladier " a été à bien des égards une sorte de préfiguration de Vichy, mais enfin, c'est bien la III République qui a créé la Caisse centrale et l'a chargée l'année d'après de prêter aux coopératives artisanales, et non Pétain...

Elle a donc continué, après 1940, à remplir cette mission conformément aux directives gouvernementales, comme l'ont fait dans leurs secteurs respectifs le Crédit national, le Crédit foncier et les autres institutions financières spécialisées. Son existence n’avait donc pas à être mise en cause à la Libération.

L'épuration n'aurait pu concerner que tel ou tel de ses dirigeants - alors fort peu nombreux s'il avait été accusé de collaboration avec l'ennemi. A ma connaissance, rien de tel ne s'est produit... 